\title{
A comparative study on selecting urban renewal project via different MADM methods
}

\author{
G. Polat, H. Turkoglu*, A. Damci, I. Demirli \\ Istanbul Technical University, Department of Civil Engineering, Istanbul, Turkey
}

\begin{abstract}
"Urban renewal" has emerged as a real alternative to prevent potential earthquake damages. Since Turkey is located in the seismic zone and exposed to severe earthquakes, there has been a great need for urban renewal projects in the last 20 years. As a result of this need, urban renewal projects have constituted an important proportion of the growth in the Turkish construction industry. Selecting the right urban renewal project is one of the vital decisions for contractors as they are taking more risk than the other parties. However, it is a challenging and time-consuming process as there are various compromising and conflicting that need to be considered simultaneously. Therefore, this selection problem should be considered as a multi-attributedecision-making (MADM) process. The main objectives of this study are to propose an integrated approach, which uses the combination of different MADM methods, for selection of urban renewal projects in Turkey, and to compare the findings of these methods with each other. Analytic Hierarchy Process (AHP) method was combined with Technique for Order Preference by Similarity to Ideal Solution (TOPSIS), VlseKriterijuska Optimizacija I Komoromisno Resenje (VIKOR), COmplex PRoportional Assessment (COPRAS), and Evaluation based on Distance from Average Solution (EDAS) methods. In the proposed approach, AHP was used to calculate the weights of the criteria that may affect the urban renewal project selection decision and the other MADM methods were used to rank the alternative projects. A case study was carried out in order to illustrate how the integrated approach can be applied in a real-life problem. The findings of using these methods were compared to each other. Application of the proposed approach revealed that it can be a useful tool in selecting urban renewal projects.
\end{abstract}

\section{Keywords}

Project selection; Urban renewal project; MADM methods; Comparative study; Case study

Received: 10 July 2019; Accepted: 11 September 2019

ISSN: 2630-5771 (online) C 2019 Golden Light Publishing All rights reserved.

\section{Introduction}

The construction industry, which accounts for about $8-9 \%$ of GDP and employs 2 million people, plays an important role in Turkey's economic development [1,2]. This industry became more crucial after the devastating earthquake that occurred in the Marmara Region in 1999. Turkey is one of the world's most vulnerable countries to earthquake [3]. Therefore, urban renewal has emerged as a real alternative to prevent potential earthquake damages [4]. In the context of the urban renewal, existing buildings, which are detected as damaged, are reconstructed. Consequently, there has been a great need for urban renewal projects in the Turkish construction industry, particularly in the last 20 years [2]. In this context, Istanbul has become a specific focus of many urban renewal

\footnotetext{
Corresponding author

Email: hturkoglu@itu.edu.tr
} 
projects as there are too many buildings (e.g., residential buildings, commercial buildings, institutional building, etc.) that are not sufficiently safe to survive during a severe earthquake. In typical urban renewal projects, public authorities purchase properties from many different private owners, renew and resell them to other private owners $[5,6]$. However, it should be stated that the execution of urban renewal projects in Turkey is different from the execution of typical urban renewal projects because of regulations laid down by government authorities. In Turkey, public authorities are not directly involved in the purchase, renewal and resale of properties, but in forming regulations that guide the planning and implementation of urban renewal projects. Residents living in the urban renewal districts specified by public authorities hire a contractor to renew their buildings. The contractor undertakes to reconstruct the building in return of the ownership of several units. To support the renovation of unsafe buildings, the rules for planning and execution of urban renewal projects allow owners to build more square meters when hiring a contractor to renew their building.

Selecting the most appropriate project is one of the vital decisions for construction companies, which in turn plays an important role in achieving good project performance and targeted profitability [7]. At this point, selecting the right urban renewal project is gaining importance for contractors as they are taking more risk than other involved stakeholders. However, it is a difficult and timeconsuming process as there are various quantitative and qualitative criteria, some of which are compromising and conflicting, that need to be taken into consideration. Therefore, this selection problem should be considered as a MADM process. Several studies have been carried out over the past few years to develop a project selection model in the literature [7-14]. However, it is hard to develop a generic model for selecting the most appropriate project because the factors affecting the selection of a construction project may differ depending on the type of the construction project in question.
Previous studies on the topic have shown that most contractors make their bidding decisions based on their own experience and intuition, in other words, they do not use any scientific method. However, in such decision-making problems, it is suggested that these decisions should be made using a number of decision support models to prevent errors and subsequently damage to the company's reputation in the market [15]. Hence, construction companies can take advantage of having a tool to help them in selecting a specific type of construction project in today's competitive construction environment. Urban renewal projects comprise an essential part of the construction projects carried out by construction companies in Turkey. Indeed, large numbers of micro-scale and small-scale construction companies have survived in the industry thanks to urban renewal projects. Therefore, an integrated approach, which uses the combination of different MADM techniques, was proposed for selecting the most appropriate urban renewal project and the findings of these techniques were compared with each other in this study. For this purpose, Analytic Hierarchy Process (AHP) technique was combined with Technique for Order Preference by Similarity to Ideal Solution (TOPSIS), VlseKriterijuska Optimizacija I Komoromisno Resenje (VIKOR), COmplex PRoportional Assessment (COPRAS), and Evaluation based on Distance from Average Solution (EDAS) methods. In the proposed approach, AHP was used to calculate the weights of the criteria that may affect the urban renewal project selection decision and the other MADM techniques were used to rank the alternative projects. A case study was also carried out in order to illustrate how the integrated approach can be applied in a real-life problem. The case study focused on a project selection problem for a Turkish construction company, which is mainly specialized in urban renewal projects. The findings of using these techniques were compared to each other.

\section{Research methodology}

The main objectives of this study are to propose an integrated approach, which uses the combination of 
different MADM techniques, for selection of urban renewal projects in Turkey, and to compare the findings of these techniques with each other. Any construction company interested in urban renewal projects can adopt and adjust the proposed approach for its own problems. The processes carried out in this study can be summarized in four basic steps as follows: (1) identifying the factors affecting the selection of appropriate urban renewal projects; (2) employing the steps of AHP method to calculate the weights of the criteria that may affect the urban renewal project selection decision; (3) employing the steps of TOPSIS, VIKOR, COPRAS and EDAS methods to rank the alternative projects for a Turkish construction company, which is primarily specialized in urban renewal projects; and (4) comparing the findings with each other (see Fig. 1). The following subsections provide a brief overview of the AHP, TOPSIS, VIKOR, COPRAS and EDAS methods.

\subsection{The AHP method}

AHP is one of the MADM methods, which was initially developed in 1980 by Thomas L. Saaty as a mathematical theory [16]. AHP allows decisionmakers to model problems in a hierarchical framework that demonstrates the interactions among the goal, main criteria, sub-criteria, and alternatives of the problem [17]. Since AHP is simple to understand by decision-makers, it has been commonly used in many different disciplines and has been implemented in almost all multiattribute decision-making applications. The steps of the AHP method are explained below [18]:

- Step 1: Defining the hierarchical framework of the decision problem (i.e., goal, main criteria, sub-criteria, alternatives).

- Step 2: Constructing pairwise comparison matrices that allow numerical representations of relations between two elements in the hierarchy through the use of the Saaty Rating Scale (see Table 1).

- Step 3: Calculating the consistency ratio signifying whether the matrices constructed are consistent.
- Step 4: Determining the priorities of the alternatives according to the main criteria and/or sub-criteria.

\subsection{The TOPSIS method}

TOPSIS, which was developed in 1981 by Hwang and Yoon, is one of the most commonly used multiattribute decision-making methods [19]. The method is a fairly simple method as it does not include complex mathematical models and algorithms. This method is used in many areas

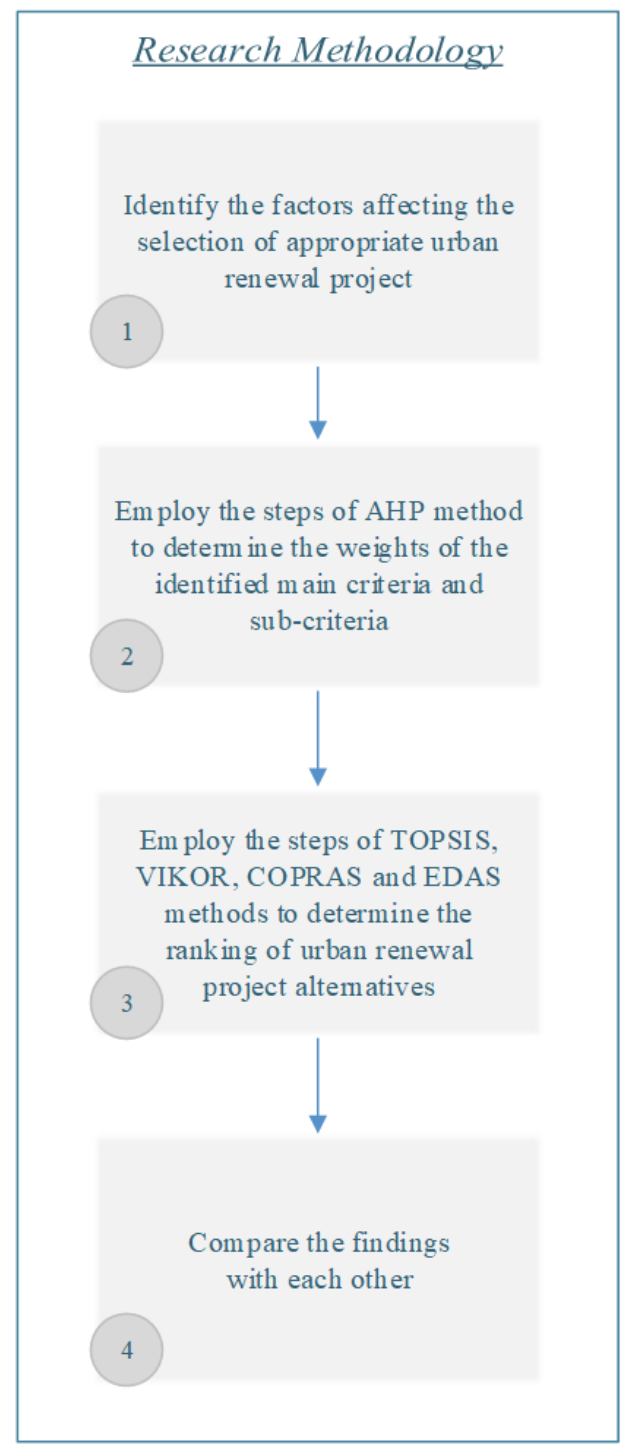

Fig. 1. The basic steps of the urban renewal project selection process. 
Table 1. Saaty's rating scale

\begin{tabular}{cll}
$\begin{array}{c}\text { Intensity } \\
\text { of } \\
\text { importance }\end{array}$ & Definition & Explanation \\
\hline 1 & $\begin{array}{l}\text { Equal importance } \\
\text { Somewhat more } \\
\text { important }\end{array}$ & $\begin{array}{l}\text { Two factors contribute equally to the objective. } \\
\text { Experience and judgment slightly favor one over the other. }\end{array}$ \\
5 & $\begin{array}{l}\text { Much more important } \\
\text { Very much important }\end{array}$ & $\begin{array}{l}\text { Experience and judgment strongly favor one over the other. } \\
\text { Experience and judgment very strongly favor one over the } \\
\text { other. }\end{array}$ \\
9 & $\begin{array}{l}\text { Absolutely more } \\
\text { important }\end{array}$ & $\begin{array}{l}\text { The evidence favoring one over the other is one of the highest } \\
\text { possible validity. } \\
\text { When compromise is needed. }\end{array}$ \\
\hline
\end{tabular}

because it is easy to understand and interpret the results. This method's fundamental principle is to create a positive ideal solution and a negative ideal solution. The method takes into account the proximity of the decision alternatives to the ideal solution [20]. The calculation steps of the method are very simple and clear, which are explained shortly below [21]:

- Step 1: Construction of the initial decision matrix $X$ with $n$ number of alternatives $(n=1$, $\ldots ., i)$ and $m$ number of criteria $(m=1, \ldots, j)$.

- Step 2: Normalization of the decision matrix elements.

- Step 3: Creation of the weighted normalization matrix.

- Step 4: Determination of positive and negative ideal solutions $A^{+}(P I S)$ and $A^{-}(N I S)$, respectively.

- Step 5: Calculation of the separation measures $\left(S_{i}^{+}, S_{i}^{-}\right)$of each alternative from the positive ideal solution and the negative ideal solution, respectively.

- Step 6: Calculation of the relative closeness $\left(C_{i}\right)$ of each alternative to the ideal solution.

- Step 7: Ranking alternatives in descending order, sorting by $C_{i}$ values.

\subsection{The VIKOR method}

Opricovic and Tzeng developed the VIKOR method in 2004 as a multi-attribute decisionmaking method for solving certain decision making problems that are not measured by the same unit and have conflicting criteria [22]. The method is an important tool in multi - attribute decision making, especially in a situation where decision makers are unable to express their preferences at the start of system design. By focusing on ranking and selecting a set of specific alternatives, this method offers compromise solutions to problems with conflicting criteria. By this way, the method assists decision-makers in making the final decision [23]. Under the assumption that each alternative is assessed for each criterion by comparing the proximity values to the ideal solution, a compromise solution is obtained. The VIKOR method takes into account the maximum group utility and the minimum individual regret. The method's calculation steps are very simple and straightforward, which are explained briefly below [22]:

- Step 1: Construction of the initial decision matrix $X$ with $n$ number of alternatives $(n=1$, $\ldots . ., i)$ and $m$ number of criteria $(m=1, \ldots, j)$.

- Step 2: Identification of the positive ideal solutions of $n$ alternatives according to each criterion $j\left(f_{j}^{*}\right)$ and the negative ideal solutions of $n$ alternatives according to each criterion $j\left(f_{j}^{-}\right.$ ) .

- Step 3: Normalization of the decision matrix elements.

- Step 4: Calculation of the $S_{i}$ (the maximum group utility, which is the distance between alternative $i$ and the positive ideal solution $f_{j}^{*}$ ) and the $R_{i}$ (the minimum individual regret of the opponent, which is the distance between alternative $i$ and the negative ideal solution $f_{j}^{-}$). 
- Step 5: Calculation of the $Q_{i}$ (the VIKOR index for each alternative $i$, which is computed using the weight of the strategy of the maximum group utility $q$ ).

- Step 6: Ranking alternatives in decreasing order, sorting by $Q_{i}$ values.

- Step 7: Proposing the alternative $\left(A_{1}\right)$, which is ranked best by the $Q_{i}$ (minimum) measure, as a compromise solution if the following two conditions are met:

Condition 1. "Acceptable advantage"

$$
Q\left(A_{2}\right)-Q\left(A_{1}\right) \geq \frac{1}{n-1}
$$

where $A_{2}$ is the alternative with the second position in the ranking list by $Q_{i} ; n$ is the number of alternatives.

Condition 2. "Acceptable stability in decision making"

Alternative $A_{l}$ must also be the best ranked by $S_{i}$ or/and $R_{i}$. This compromise solution is stable within a decision making process, which could be: "voting by majority rule" (when $q>0.5$ is needed), or by consensus" ( $q \approx 0.5)$, or "with veto" $(q<0.5)$.

If one of the conditions is not satisfied, then a set of compromise solutions is proposed, which consists of:

$\checkmark$ Alternatives $A_{1}$ and $A_{2}$ if only Condition 2 is not satisfied, or

$\checkmark$ Alternatives $A_{l}, A_{2}, \ldots, A_{K}$ if Condition 1 is not satisfied; and $A_{K}$ is determined by using Equation 2 for maximum $K$.

$$
Q\left(A_{K}\right)-Q\left(A_{1}\right) \approx \frac{1}{n-1}
$$

The best alternative is the one with the minimum value of $Q_{i}$. The main ranking result is the compromise ranking list of alternatives, and the compromise solution with the "advantage rate".

\subsection{The COPRAS method}

The COPRAS method was first introduced in 1994 by Zavadskas, Kaklauskas and Sarka [24]. By considering the weights of the criteria, this method compares the alternatives and determines their priorities under the conflicting criteria. The ranking of alternatives by using the COPRAS method suggests direct and proportional dependence on the significance and utility degree (priority) [25]. The COPRAS method can be applied easily to problems involving complex criteria and a wide range of alternatives. There are numerous applications of COPRAS method in the literature. For the COPRAS method, the following steps are applied:

- Step 1: Construction of the initial decision matrix $X$ with $n$ number of alternatives $(n=1$, ....,,$i)$ and $m$ number of criteria $(m=1, \ldots, j)$.

- Step 2: Normalization of the decision matrix elements.

- Step 3: Creation of the weighted normalization matrix.

- Step 4: Calculation of the sums of weighted normalized values $\left(S_{i}^{+}, S_{i}^{-}\right)$for both the beneficial and non-beneficial criteria.

- Step 5: Determination the relative significances of the alternatives, $Q_{i}$.

- Step 6: Calculation of the quantitative utility, $U_{i}$, for each alternative.

- Step 7: Ranking alternatives in decreasing order, sorting by $U_{i}$ values.

\subsection{The EDAS method}

The EDAS method was proposed in 2015 by Keshavarz Ghorabaee et al [26]. Although EDAS method is a relatively new method in the literature, it has been observed that it is widely used for solving many MADM problems. The EDAS method's computational process can be identified as highly innovative and is also based on verified approaches used in some prominent MADM methods such as: SAW, TOPSIS, and VIKOR. One of the superior functionalities of this method is that it requires less data and less computational process. The fundamental principles of the EDAS method are to use two distance measurements, namely the Positive Distance from Average (PDA) and the Negative Distance from Average (NDA); and to evaluate the alternatives according to higher PDA values and lower NDA values. The steps in the EDAS method are summarized as follows [27]: 
- Step 1: Construction of the initial decision matrix $X$ with $n$ number of alternatives $(n=1, \ldots$, i) and $m$ number of criteria $(m=1, \ldots, j)$.

- Step 2: Determination of the average solution according to all criteria.

- Step 3: Calculation of the positive distance from average $(P D A)$ and the negative distance from average (NDA) matrices according to the type of criteria (beneficial and non-beneficial).

- Step 4: Determination of the weighted sum of $P D A$ and NDA for all alternatives.

- Step 5: Normalization of the values of $S P_{i}$ and $S N_{i}$ for all alternatives.

- Step 6: Calculation of the appraisal score $\left(A S_{i}\right)$ for all alternatives.

- Step 7: Ranking the alternatives according to the decreasing values of appraisal score $\left(A S_{i}\right)$.

\section{A numerical application of the proposed approach: Case of the urban renewal project selection}

A case study, which was formerly studied by Polat et al. in 2016 [28], was selected in order to illustrate how the integrated approach can be applied in a real-life problem. The case study focused on a project selection problem for a Turkish construction company, which is mainly specialized in urban renewal projects. The company wants to select the most appropriate urban renewal project from twelve alternatives. The decision hierarchy was developed based on opinions and evaluations of the contractor's team consisting of three members, who are highly experienced and in charge of the urban renewal project selection process in the construction company.

\subsection{Decision hierarchy of the urban renewal project selection problem}

There are four main levels in the developed decision hierarchy. The first level is the overall goal of the decision process, which is defined as "selection of the most appropriate urban renewal project". In the second level, there are main criteria. The sub-criteria under main criteria are on the third level of the decision hierarchy. The alternative projects are on the fourth level of the decision hierarchy. After conducting face-to-face interviews with contractor's team members and carrying out an extensive review of related literature, 7 main criteria were identified, which include: company related factors (MC-1), project related factors (MC2 ), cost related factors (MC-3), contract related factors (MC-4), profit related factors (MC-5), management capability related factors (MC-6), finance related factors (MC-7). 17 sub-criteria under the 7 main criteria were determined, namely reputation (SC1-1), gaining experience (SC1-2), experience in similar works (SC2-1), familiarity with the location of the project (SC2-2), size of the project (SC2-3), duration of the project (SC2-4), cost of the construction work (SC3-1), other costs (SC3-2), penalty (SC4-1), fair contract clauses related to the dispute resolution (SC4-2), rate of return of investment (SC5-1), duration of return of investment (SC5-2), closeness of the construction site to the head office (SC6-1), safety of the construction site (SC6-2), accessibility of the construction site (SC6-3), amount of credit needed (SC7-1), amount of bond needed (SC7-2), which should be considered during the project selection process in the case study. The specialists stated that these criteria were unique to the studied case's conditions and may change from project to project, as the criteria affecting the selection of a construction project may differ depending on the type of the construction project in question. There are twelve different urban renewal project alternatives for the contractor, which are: (P-1), (P2), (P-3), (P-4), (P-5), (P-6), (P-7), (P-8), (P-9), (P10), (P-11) and (P-12). The decision hierarchy of the most appropriate urban renewal project selection problem is presented in Fig. 2.

\subsection{Determining the weights of the main and sub- criteria of the selection problem}

The AHP method is employed to determine the weights of the identified main criteria and sub criteria after constructing the decision hierarchy of the urban renewal project selection problem. In this step, three experienced civil engineers in the contractor's decision making team separately formed their pairwise comparison matrix and 


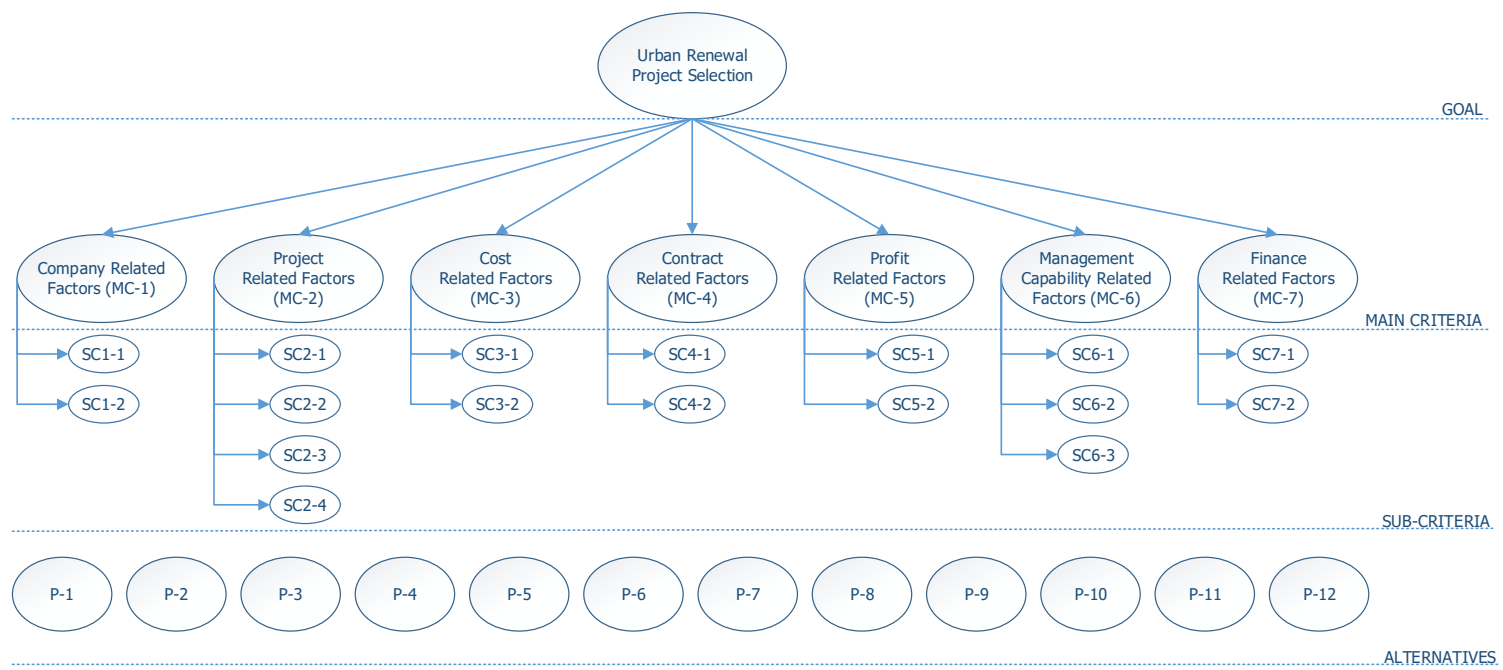

Fig. 2. Decision hierarchy of the most appropriate urban renewal project selection problem.

geometric means of these values were calculated to achieve the final pairwise comparison matrix. The final pairwise comparison matrix and the weights of the main criteria obtained from AHP computations are presented in Table 2. Microsoft (MS) Excel was utilized to implement the AHP method.

According to the findings, the "MC-3-Cost Related Factors" has the highest weight on the selection of an urban renewal project problem. It is followed by the "MC-5- Profit Related Factors" with second higher weight. On the other hand, the "MC-6- Management Capability Related Factors" has the least importance on the selection process as it has the lowest weight. It is necessary to check the consistency ratio (CR) of the comparison matrix after aggregating group decisions. The $\mathrm{CR}$ of the pairwise comparison matrix was found to be 0.04 . Since it is below the 0.10 , it can be concluded that the judgment matrix is consistent and the weights can be used in the selection process.

\subsection{Finding the preferences of the urban renewal project alternatives with TOPSIS, VIKOR, COPRAS and EDAS methods}

After obtaining the weights of the main criteria and sub-criteria of the urban renewal project selection problem using the AHP method, TOPSIS, VIKOR, COPRAS and EDAS methods was employed to determine the ranking of twelve urban renewal project alternatives. The first step of the TOPSIS,
VIKOR, COPRAS and EDAS methods is to construct the decision matrix by the decision making team when the AHP computations are over. For this purpose, in the urban renewal project selection problem, the preferences of three decision makers were collected to construct the decision matrix. The data of "size of the project (SC2-3), duration of the project (SC2-4), cost of the construction work (SC3-1), other costs (SC3-2), penalty (SC4-1), rate of return of investment (SC51), duration of return of investment (SC5-2), amount of credit needed (SC7-1), and amount of bond needed (SC7-2) are quantitative, whereas the other sub-criteria are qualitative and these values were obtained using 1 to 9 point scale (i.e., 1: Very Bad; 9: Very Good).

In order to construct an aggregated decision matrix of the urban renewal project selection problem, geometric means of the individual evaluations of the decision makers on the alternatives were calculated (see Table 3). In this selection problem, SC2-3, SC2-4, SC3-1, SC3-2, SC4-1, SC5-2, SC7-1 and SC7-2 are non-beneficial sub-criteria where the smaller value is always preferred. The rest of them are beneficial subcriteria where the larger values are desirable. Therefore, SC2-3, SC2-4, SC3-1, SC3-2, SC4-1, SC5-2, SC7-1 and SC7-2 sub-criteria are minimized and the rest of them are maximized. 
Table 2. Aggregated pairwise matrix of main criteria for the urban renewal project selection problem

\begin{tabular}{ccccccccc}
\hline Criteria & MC-1 & MC-2 & MC-3 & MC-4 & MC-5 & MC-6 & MC-7 & Weights \\
\hline MC-1 & 1.00 & 0.28 & 0.16 & 1.59 & 0.22 & 2.00 & 0.30 & 0.05 \\
MC-2 & 3.63 & 1.00 & 0.25 & 4.31 & 0.33 & 4.64 & 2.62 & 0.15 \\
MC-3 & 6.32 & 4.00 & 1.00 & 7.00 & 2.62 & 7.00 & 4.00 & 0.38 \\
MC-4 & 0.63 & 0.23 & 0.14 & 1.00 & 0.22 & 1.59 & 0.25 & 0.04 \\
MC-5 & 4.64 & 3.00 & 0.38 & 4.64 & 1.00 & 5.31 & 3.30 & 0.23 \\
MC-6 & 0.50 & 0.22 & 0.14 & 0.63 & 0.19 & 1.00 & 0.23 & 0.03 \\
MC-7 & 3.30 & 0.38 & 0.25 & 4.00 & 0.30 & 4.31 & 1.00 & 0.12 \\
\hline
\end{tabular}

Table 3. Initial decision matrix.

\begin{tabular}{|c|c|c|c|c|c|c|c|c|c|c|c|c|c|c|}
\hline Sub-Criteria & Unit & P-1 & P-2 & P-3 & $\mathrm{P}-4$ & P-5 & P-6 & P-7 & P-8 & P-9 & $\mathrm{P}-10$ & P-11 P-12 & Neights & s Opt. Dir. \\
\hline SC1-1 & S.S* & 3.00 & 9.00 & 3.30 & 7.32 & 6.32 & 8.32 & 8.32 & 9.00 & 4.31 & 5.31 & 2.002 .00 & 0.04 & $\uparrow$ \\
\hline SC1-2 & S.S* & 2.00 & 6.65 & 3.30 & 9.00 & 9.00 & 5.65 & 6.65 & 6.32 & 2.52 & 6.00 & 4.003 .30 & 0.01 & $\uparrow$ \\
\hline SC2-1 & S.S* & 9.00 & 9.00 & 9.00 & 1.59 & 2.62 & 9.00 & 9.00 & 9.00 & 9.00 & 9.00 & 9.009 .00 & 0.03 & $\uparrow$ \\
\hline SC2-2 & S.S* & 7.61 & 9.00 & 3.30 & 5.94 & 1.26 & 9.00 & 9.00 & 9.00 & 5.65 & 8.28 & 3.301 .26 & 0.01 & $\uparrow$ \\
\hline $\mathrm{SC} 2-3$ & $\mathrm{~m}^{2}$ & 1230 & 02422 & 2238 & 12480 & 8640 & 2657 & 3726 & 62898 & 31904 & 5382 & 43003281 & 0.09 & $\downarrow$ \\
\hline SC2-4 & Month & 12 & 18 & 18 & 24 & 18 & 16 & 18 & 18 & 16 & 18 & $16 \quad 18$ & 0.02 & $\downarrow$ \\
\hline SC3-1 & $\mathrm{TL}\left(\mathrm{x} 10^{3}\right)$ & 1845 & 54844 & +3917 & 22419 & 15920 & 5314 & 17452 & 25796 & 63332 & 10764 & 473105742 & 0.33 & $\downarrow$ \\
\hline SC3-2 & $\mathrm{TL}\left(\mathrm{x} 10^{3}\right)$ & 98 & 1890 & 1116 & 3938 & 2094 & 1034 & 1674 & 41500 & 738 & 1344 & 524730 & 0.04 & $\downarrow$ \\
\hline SC4-1 & $\mathrm{TL}\left(\mathrm{x} 10^{3}\right)$ & 6 & 30 & 18 & 25 & 20 & 16 & 25 & 25 & 15 & 25 & $15 \quad 18$ & 0.03 & $\downarrow$ \\
\hline SC4-2 & S.S* & 6.32 & 3.30 & 6.32 & 1.59 & 2.29 & 4.31 & 4.31 & 3.30 & 6.32 & 4.64 & 7.008 .65 & 0.01 & $\uparrow$ \\
\hline SC5-1 & $\%$ & 0.85 & 0.26 & 0.25 & 0.25 & 0.42 & 0.26 & 0.25 & 0.21 & 0.38 & 0.39 & 0.290 .30 & 0.07 & $\uparrow$ \\
\hline SC5-2 & Month & 24 & 30 & 30 & 36 & 30 & 28 & 30 & 30 & 24 & 28 & $28 \quad 30$ & 0.16 & $\downarrow$ \\
\hline SC6-1 & S.S* & 5.94 & +9.00 & 5.94 & 5.94 & 3.63 & 9.00 & 9.00 & 8.65 & 8.65 & 8.65 & 3.632 .00 & 0.01 & $\uparrow$ \\
\hline SC6-2 & S.S* & 5.00 & 9.00 & 5.31 & 5.00 & 3.91 & 7.32 & 1.52 & 29.00 & 5.31 & 5.94 & 2.621 .00 & 0.02 & $\uparrow$ \\
\hline SC6-3 & S.S* & 7.00 & 4.31 & 6.65 & 7.00 & 3.30 & 5.59 & 5.59 & 4.64 & 7.00 & 5.94 & 5.948 .00 & 0.01 & $\uparrow$ \\
\hline SC7-1 & $\mathrm{TL}\left(\mathrm{x} 10^{3}\right)$ & 0 & 0 & 0 & 5000 & 3000 & 0 & 1000 & $0 \quad 0$ & 0 & 2000 & $1000 \quad 0$ & 0.10 & $\downarrow$ \\
\hline SC7-2 & $\mathrm{TL}\left(\mathrm{x} 10^{3}\right)$ & 0 & 3000 & 3000 & 5000 & 4000 & 3000 & 3000 & 03000 & 2500 & 3000 & 25002000 & 0.02 & $\downarrow$ \\
\hline
\end{tabular}

*S.S.: Subjective Score

After forming the aggregated decision matrix, the steps of TOPSIS, VIKOR, COPRAS and EDAS methods were followed respectively via Microsoft (MS) Excel.

The results of TOPSIS method are presented in Table 4.

The final ranking of the urban renewal project alternatives was determined with the TOPSIS method as $\mathrm{P}-1>\mathrm{P}-9>\mathrm{P}-3>\mathrm{P}-2>\mathrm{P}-6>\mathrm{P}-12>\mathrm{P}-8>\mathrm{P}-$ $11>\mathrm{P}-7>\mathrm{P}-10>\mathrm{P}-5>\mathrm{P}-4$. Based on the ranking results, $\mathrm{P}-1$ is the best alternative with maximum $C_{i}$ value. P-1 alternative was selected as the most appropriate alternative based on the information provided by the TOPSIS ranking. It is followed by P-9 with the second higher $C_{i}$ value. On the other hand, P-5 and P-4 ranked eleventh and twelfth, respectively.

The results of VIKOR method are presented in Table 5. 
Table 4. Result matrix of TOPSIS method.

\begin{tabular}{lllll}
\hline Alternatives & $S_{i}^{+}$ & $S_{i}^{-}$ & $C_{i}$ & Ranking \\
\hline P-1 & 0.016 & 0.229 & 0.936 & 1 \\
P-2 & 0.048 & 0.198 & 0.806 & 4 \\
P-3 & 0.042 & 0.206 & 0.830 & 3 \\
P-4 & 0.229 & 0.015 & 0.062 & 12 \\
P-5 & 0.154 & 0.077 & 0.334 & 11 \\
P-6 & 0.048 & 0.194 & 0.801 & 5 \\
P-7 & 0.069 & 0.168 & 0.709 & 9 \\
P-8 & 0.055 & 0.189 & 0.775 & 7 \\
P-9 & 0.032 & 0.213 & 0.870 & 2 \\
P-10 & 0.100 & 0.132 & 0.569 & 10 \\
P-11 & 0.067 & 0.169 & 0.714 & 8 \\
P-12 & 0.053 & 0.189 & 0.780 & 6 \\
\hline
\end{tabular}

Table 5. Result matrix of VIKOR method.

\begin{tabular}{lllllll}
\hline Alternatives & $S_{i}$ & $R_{i}$ & $Q_{i}$ & Ranking & Checking Conditions & × \\
P-1 & 0.066 & 0.034 & 0.000 & 1 & C1. 0.090=0.090 & $\checkmark$ \\
P-2 & 0.292 & 0.080 & 0.210 & 4 & C2. P-1 $\left(R_{i}\right)=\min \left(R_{i}\right)$ & \\
P-3 & 0.302 & 0.080 & 0.216 & 5 & \\
P-4 & 0.919 & 0.330 & 1.000 & 12 & \\
P-5 & 0.627 & 0.226 & 0.652 & 11 & \\
P-6 & 0.250 & 0.065 & 0.159 & 3 & \\
P-7 & 0.360 & 0.090 & 0.267 & 9 & \\
P-8 & 0.306 & 0.080 & 0.218 & 6 & \\
P-9 & 0.171 & 0.051 & 0.090 & 2 & \\
P-10 & 0.423 & 0.143 & 0.393 & 10 & \\
P-11 & 0.364 & 0.088 & 0.265 & 8 & \\
P-12 & 0.347 & 0.080 & 0.242 & 7 & \\
\hline
\end{tabular}

Based on the ranking results, although $\mathrm{P}-1$ is the best alternative with minimum $Q_{i}$ value, $\mathrm{P}-1$ and $\mathrm{P}-$ 9 are compromise solutions because P-1 does not satisfy the "acceptable advantage" condition. P-1 and P-9 alternatives were selected as the most compromising alternatives based on the information provided by the VIKOR ranking. According to the ranking results, P-5 and P-4 ranked eleventh and twelfth, respectively.

The results of COPRAS method are presented in Table 6.
Based on the ranking results, $\mathrm{P}-1$ is the best alternative with maximum $Q_{i}$ and $U_{i}$ values. P-1 alternative was selected as the most appropriate alternative based on the information provided by the COPRAS ranking. It is followed by P-9 with the second higher $Q_{i}$ and $U_{i}$ values. On the other hand, P-5 and P-4 ranked eleventh and twelfth, respectively.

The results of EDAS method are presented in Table 7. 
Table 6. Result matrix of COPRAS method.

\begin{tabular}{llllll}
\hline Alternatives & $S_{i}^{+}$ & $S_{i}{ }^{-}$ & $Q_{i}$ & $U_{i}(\%)$ & Ranking \\
\hline P-1 & 0.025 & 0.022 & 0.173 & 100.00 & 1 \\
P-2 & 0.020 & 0.047 & 0.089 & 51.37 & 5 \\
P-3 & 0.014 & 0.040 & 0.095 & 55.16 & 3 \\
P-4 & 0.015 & 0.176 & 0.033 & 19.13 & 12 \\
P-5 & 0.016 & 0.121 & 0.042 & 24.51 & 11 \\
P-6 & 0.019 & 0.044 & 0.093 & 53.58 & 4 \\
P-7 & 0.019 & 0.065 & 0.068 & 39.61 & 8 \\
P-8 & 0.019 & 0.049 & 0.084 & 48.76 & 6 \\
P-9 & 0.018 & 0.033 & 0.117 & 67.38 & 2 \\
P-10 & 0.019 & 0.086 & 0.057 & 32.68 & 10 \\
P-11 & 0.013 & 0.060 & 0.067 & 38.58 & 9 \\
P-12 & 0.013 & 0.046 & 0.082 & 47.62 & 7 \\
\hline
\end{tabular}

Table 7. Result matrix of EDAS method.

\begin{tabular}{lllllll}
\hline Alternatives & $S P_{i}$ & $N P_{i}$ & $N S P_{i}$ & $N N P_{i}$ & $A S_{i}$ & Ranking \\
\hline P-1 & 0.557 & 0.116 & 1.000 & 0.914 & 0.957 & 2 \\
P-2 & 0.289 & 0.088 & 0.519 & 0.935 & 0.727 & 6 \\
P-3 & 0.366 & 0.016 & 0.656 & 0.988 & 0.822 & 4 \\
P-4 & 0.053 & 1.344 & 0.095 & 0.000 & 0.047 & 12 \\
P-5 & 0.048 & 0.690 & 0.086 & 0.486 & 0.286 & 10 \\
P-6 & 0.283 & 0.039 & 0.509 & 0.971 & 0.740 & 5 \\
P-7 & 0.050 & 0.063 & 0.090 & 0.953 & 0.521 & 8 \\
P-8 & 0.029 & 0.034 & 0.440 & 0.457 & 0.449 & 9 \\
P-9 & 0.065 & 0.004 & 1.000 & 0.931 & 0.965 & 1 \\
P-10 & 0.003 & 0.033 & 0.040 & 0.481 & 0.260 & 11 \\
P-11 & 0.033 & 0.005 & 0.505 & 0.918 & 0.711 & 7 \\
P-12 & 0.058 & 0.004 & 0.893 & 0.931 & 0.912 & 3 \\
\hline
\end{tabular}

The final ranking of the urban renewal project alternatives was determined with the EDAS method as $\quad \mathrm{P}-9>\mathrm{P}-1>\mathrm{P}-12>\mathrm{P}-3>\mathrm{P}-6>\mathrm{P}-2>\mathrm{P}-11>\mathrm{P}-7>\mathrm{P}-$ $8>\mathrm{P}-5>\mathrm{P}-10>\mathrm{P}-4$. Based on the ranking results, $\mathrm{P}-9$ is the best alternative with maximum $A S_{i}$ value. $\mathrm{P}$ 9 alternative was selected as the most appropriate alternative based on the information provided by the EDAS ranking. It is followed by $\mathrm{P}-1$ with the second higher $A S_{i}$ value. On the other hand, P-10 and $\mathrm{P}-4$ ranked eleventh and twelfth, respectively.
As a result of the application of TOPSIS, VIKOR, COPRAS and EDAS methods, the rankings of the alternatives according to these methods are presented collectively in Table 8 and Fig. 3. Thus, the interpretation of the findings obtained from the methods is both easy and reasonable. It also helps readers see the big frame to assess of alternatives for selection of urban renewal projects. 
Table 8. The rankings of the alternatives according to TOPSIS, VIKOR, COPRAS and EDAS methods

\begin{tabular}{ccccc}
\hline Alternatives & TOPSIS & VIKOR & COPRAS & EDAS \\
\hline P-1 & 1 & 1 & 1 & 2 \\
P-2 & 4 & 4 & 5 & 6 \\
P-3 & 3 & 5 & 3 & 4 \\
P-4 & 12 & 12 & 12 & 12 \\
P-5 & 11 & 11 & 11 & 10 \\
P-6 & 5 & 3 & 4 & 5 \\
P-7 & 9 & 9 & 8 & 8 \\
P-8 & 7 & 6 & 6 & 9 \\
P-9 & 2 & 2 & 2 & 1 \\
P-10 & 10 & 10 & 10 & 11 \\
P-11 & 8 & 7 & 9 & 7 \\
P-12 & 6 & 7 & 7 \\
\hline
\end{tabular}

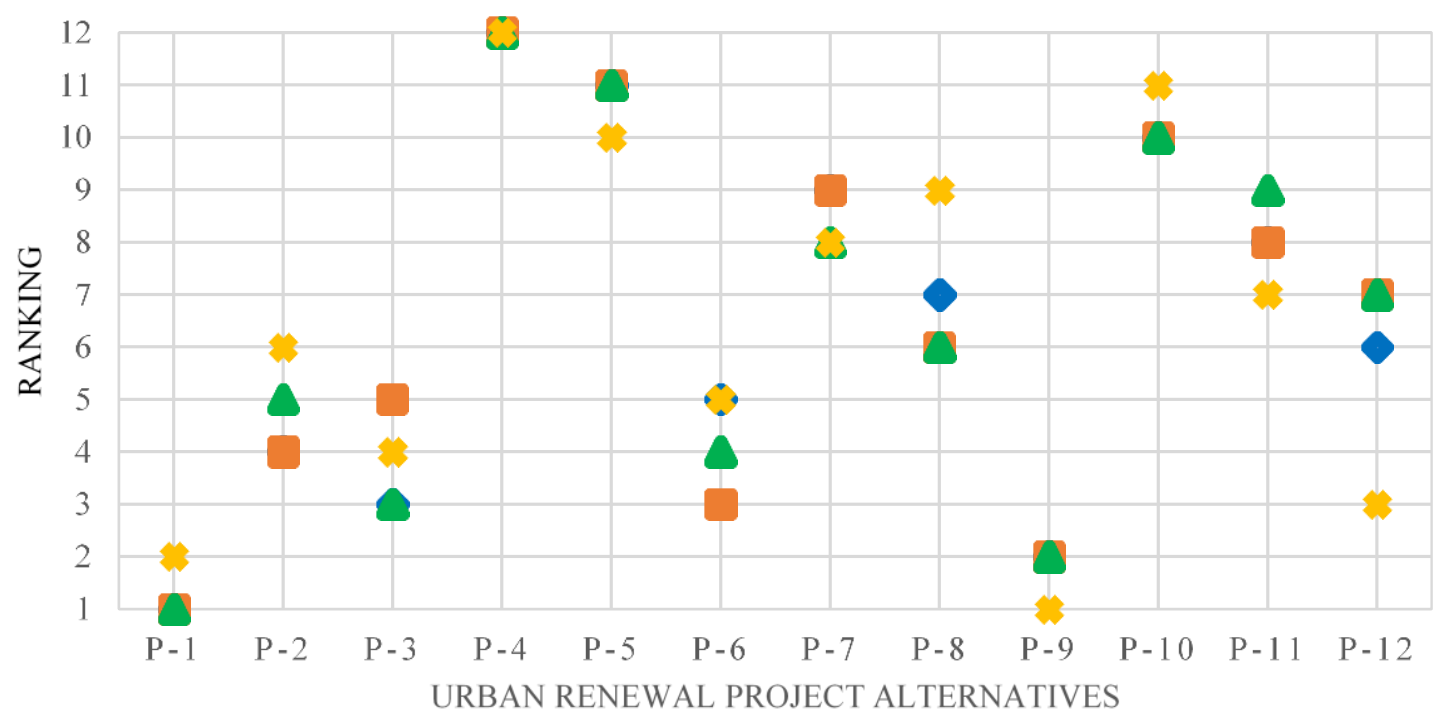

\section{TOPSIS DIKOR ACOPRAS}

Fig. 3. The rankings of the alternatives according to the TOPSIS, VIKOR, COPRAS and EDAS methods.

As presented in Table 8 and Figure 3, P-1 was ranked as the first in the TOPSIS, VIKOR and COPRAS methods and second in the EDAS method, while P-9 was ranked as the first in the EDAS method and second in the other methods. In addition, P-1 and P-9 alternatives were found to be a compromise solution in the VIKOR method. On the other hand, P-4 is ranked twelfth in all methods. It can be observed that P-1 and P-9 alternatives were selected as the most compromising alternatives, while the alternative P-4 was the worst option.

In order to check the validity of the proposed approach and its usability within the company, the results were discussed with decision makers. They stated that they would be able to apply the proposed approach in the future project selection problem for the right decisions, quicker selection process, more 
systematic evaluation, and more rationality. Application of the proposed approach revealed that it can be a useful tool in selecting projects.

\section{Conclusions}

One of the vital decisions for construction companies is selecting the most appropriate project, which in turn plays a vital role in achieving good project overall performance and targeted profitability. Especially, selecting the right urban renewal project is gaining importance for contractors because they are taking more risk than other involved stakeholders. However, it is a difficult and time-consuming process as there are various quantitative and qualitative criteria, some of which are compromising and conflicting, that need to be taken into consideration. Therefore, this selection problem should be considered as a MADM process. Previous studies on the topic have shown that most contractors make their bidding decisions based on their own experience and intuition, in other words, they do not use any scientific method. However, in such decisionmaking problems, it is suggested that these decisions should be made using a number of decision support models to prevent errors and subsequently damage to the company's reputation in the market.

This study aims to propose an integrated approach which uses the combination of different MADM methods that can assist construction companies in more rational, reasonable and unbiased selection of their urban renewal projects. In order to illustrate how the proposed integrated approach can be applied in a construction company, which predominantly undertakes urban renewal projects in Turkey, a case study was also carried out. The findings of using these techniques were compared to each other.

Based on the results, P-1 was ranked as the first in the TOPSIS, VIKOR and COPRAS methods and second in the EDAS method, while P-9 was ranked as the first in the EDAS method and second in the other methods. In addition, P-1 and P-9 alternatives were found to be a compromise solution in the VIKOR method. On the other hand, P-4 is ranked twelfth in all methods. It can be observed that P-1 and P-9 alternatives were selected as the most compromising alternatives, while the alternative $\mathrm{P}$ 4 was the worst option. In order to check the validity of the proposed approach and its applicability within the company, the results were discussed with decision makers. They stated that they would be able to apply the proposed approach in the future project selection problem for the right decisions, quicker selection process, more systematic evaluation, and more rationality. Any construction company interested in urban renewal projects can adopt and adjust the proposed approach. Fuzzy numbers can be used in future studies when assessing qualitative criteria.

\section{References}

[1] TCA (Turkish Contractors Association). (2018). "Report on Turkish International contracting services." Turkey (in Turkish).

[2] Ozorhon B (2012). Construction Industry in Turkey and Its Place in The World, Istanbul Chamber of Commerce Publications, Ankara, (in Turkish).

[3] Syngellakis S (2016). Management of Natural Disasters. WIT Press, UK / Computational Mechanics, USA.

[4] Prime Ministry, Disaster and Emergency Management Authority (AFAD). (2012). Turkey: National Earthquake Strategy and Action Plan 2012-2023 (NESAP 2012-2023). Turkey.

[5] Flaherty BO (1994). Land assembly and urban renewal. Regional Science and Urban Economics, 24, 287-300.

[6] Juan YK, Roper KO, Castro-Lacouture D, Kim JH (2010). Optimal decision making on urban renewal projects. Management Decision, 48(2), 207-224.

[7] Ebrahimnejad S, Mousavi SM, TavakkoliMoghaddam R, Hashemi H, Vahdani B (2012). A novel two-phase group decision making approach for construction project selection in a fuzzy environment. Applied Mathematical Modelling, 36, 4197-4217.

[8] Wang AM, Lee AHI, Peng LP, Wu ZL (2013). An integrated decision-making model for district revitalization and regeneration project selection. Decision Support Systems, 54, 1092-1103.

[9] Shafahi A, Haghani A (2014). Modeling contractors' project selection and markup decisions 
influenced by eminence. International Journal of Project Management, 32, 1481-1493.

[10] Taylan O, Bafail AO, Abdulaal RM, Kabli MR (2014). Construction projects selection and risk assessment by fuzzy AHP and fuzzy TOPSIS methodologies. Applied Soft Computing, 17, 105116.

[11] Pekuri A, Pekuri L, Haapasalo H (2015). Business models and project selection in construction companies. Construction Innovation, 15(2) 180197.

[12] Li F, Etienne A, Vernadat F, Siadat A (2016). Multi-criteria performance management methodology for decision support in industrial project selection problems. In 2016 IEEE International Conference on Industrial Engineering and Engineering Management (IEEM) (pp. 10961100). IEEE.

[13] Parvaneh F, El-Sayegh SM (2016). Project selection using the combined approach of AHP and LP. Journal of Financial Management of Property and Construction, 21(1), 39-53.

[14] Davoudabadi R, Mousavi SM, Šaparauskas J, Gitinavard H (2019). Solving construction project selection problem by a new uncertain weighting and ranking based on compromise solution with linear assignment approach. Journal of Civil Engineering and Management, 25(3), 241-251.

[15] Leśniak A, Plebankiewicz E (2013). Modeling the decision-making process concerning participation in construction bidding. Journal of Management in Engineering, 31(2), 04014032.

[16] Saaty TL (1980), The Analytic Hierarchy Process, McGraw-Hill, New York, NY.

[17] Najafi A, Karimpour MH, Ghaderi M (2014). Application of Fuzzy AHP Method to IOCG Prospectivity Mapping: A Case Study in Taherabad Prospecting Area, Eastern Iran, International Journal of Applied Earth Observation and Geoinformation, 33, 142-154.

[18] Saaty TL (2008). Decision making with the analytic hierarchy process. International Journal Of Services Sciences, 1(1), 83-98.

[19] Hwang CL, Yoon KS (1981). Multiple Attribute Decision Making: Methods and Applications. Berlin: Springer-Verlag.

[20] Govindan K, Shankar KM, Kannan D (2016). Sustainable material selection for construction industry-A hybrid multi criteria decision making approach. Renewable and Sustainable Energy Reviews, 55, 1274-1288.
[21] Kannan G, Pokharel S, Kumar PS (2009). A hybrid approach using ISM and fuzzy TOPSIS for the selection of reverse logistics provider. Resources, Conservation and Recycling, 54(1), 28-36.

[22] Opricovic S, Tzeng GH (2004). Compromise Solution by MCDM Methods: A Comparative Analysis of VIKOR and TOPSIS, European Journal of Operational Research, 156(2), 445-455.

[23] Büyüközkan G, Görener A (2015). Evaluation of Product Development Partners Using an Integrated AHP-VIKOR Model. Kybernetes, 44(2), 220-237.

[24] Zavadskas EK; Kaklauskas A, Sarka V (1994). The new method of multicriteria complex proportional assessment of projects. Technological and Economic Development of Economy 1(3): 131139.

[25] Ustinovichius L, Zavadkas EK, Podvezko V (2007). Application of a quantitative multiple criteria decision making (MCDM-1) approach to the analysis of investments in construction. Control and Cybernetics, 36(1), 251.

[26] Keshavarz Ghorabaee M, Zavadskas EK, Olfat L, Turskis Z (2015). Multi-criteria inventory classification using a new method of evaluation based on distance from average solution (EDAS). Informatica, 26(3), 435-451.

[27] Trinkūnienè E, Podvezko V, Zavadskas EK, Jokšienė I, Vinogradova I, Trinkūnas V (2017). Evaluation of quality assurance in contractor contracts by multi-attribute decision-making methods. Economic Research, 30(1), 1152-1180.

[28] Polat G, Damci A, Gurgun AP, Demirli I (2016). Urban renewal project selection using the integration of AHP and PROMETHEE approaches. Procedia Engineering, 164, 339-346. 